\title{
GAS ADSORPTION PROPERTIES OF ZSM-5 ZEOLITES HEATED TO EXTREME TEMPERATURES
}

\author{
María Pérez-Page ${ }^{1}$, James Makel ${ }^{1}$, Kelly Guan ${ }^{2}$, Shenli Zhang ${ }^{2}$, Joseph Tringe ${ }^{3}$, Ricardo H. R. \\ Castro $^{2}$ and Pieter Stroeve ${ }^{1^{*}}$. \\ ${ }^{1}$ Department of Chemical Engineering and ${ }^{2}$ Department of Materials Science and Engineering \\ University of California Davis, Davis, CA 95616, United States \\ ${ }^{3}$ Lawrence Livermore National Laboratory, Livermore, CA, United States
}

\section{ABSTRACT}

Zeolites are broadly useful catalysts and molecular sieve adsorbents for purification. In this work the thermal degradations of bare and platinum-loaded ZSM-5 was studied with the goal of understanding the behavior of nanoporous solids at extreme temperatures comparable to those present in nuclear fuels. Zeolites were heated in air and nitrogen at temperatures up to $1500{ }^{\circ} \mathrm{C}$, and then characterized for thermal stability via X-ray diffraction (XRD) and for, gas adsorption by the Brunauer-Emmett-Teller (BET) method. Scanning electron microscopy (SEM), differential scanning calorimetry (DSC) and thermal gravimetric analysis (TGA) were also employed. These results indicate zeolites are stable when heat-treated up to $800{ }^{\circ} \mathrm{C}$ and degrade slowly at higher temperatures. However, significant surface area degradation begins at 1025 to $1150{ }^{\circ} \mathrm{C}$ with an activation energy of $400 \mathrm{~kJ} / \mathrm{mole}$. At $1500{ }^{\circ} \mathrm{C}$, gas adsorption measurements and SEM images show complete collapse of the porous structure. Critically for nuclear fuel applications, however, the zeolites still adsorb helium in significant quantities.

*Corresponding author. Email: pstroeve@ucdavis.edu 


\section{KEY WORDS:}

26 Nanoporous solids; Surface area degradation; pore collapse; extreme temperatures; gas

27 adsorption; helium adsorption

\section{1. INTRODUCTION}

29 There are many possible applications of nanoporous solids in extreme environments. For 30 example, in a fission nuclear reaction, helium together with other fission product gases like

31 xenon are generated $[1,2]$. These gases have a low solubility and diffusion in $\mathrm{UO}_{2}[3]$ and above

32 the saturation concentration they can create micro bubbles within the fuel leading to fuel 33 swelling and increasing potential for release into the atmosphere. Materials designed to 34 capture and retain these gases may be incorporated into the fuel, but they must survive high 35 temperatures and high levels of radiation. If they are to remain functional during reprocessing 36 operations, they must also react minimally with chemicals such as nitric acid and solvents [4].

37 The fuel in high-temperature reactors is operated at temperatures between 400 and $1200{ }^{\circ} \mathrm{C}$ 38 [5], with a typical operation range of 750 to $950{ }^{\circ} \mathrm{C}$ [6]. However, fuel sintering processes are even higher, i.e. $1500{ }^{\circ} \mathrm{C}$ [7], though sintering times are much shorter in duration relative to fuel operation or storage. Microporous materials have found wide application in other areas such as

41 catalysis [8, 9], gas adsorption [10], biology [11] and many other fields. Additionally, 42 nanoporous materials with good thermal stability are of interest for use in high-temperature 43 environments for various applications $[12,13]$. In this work, we examine the feasibility of the 44 nanoporous material zeolite for capturing fission product gases, especially helium. Zeolites are nanoporous crystalline aluminosilicates consisting of a complex framework of metal oxides. 
47 volume [14], finding use as catalysts [9, 15, 16], nuclear waste treatment $[17,18]$ and even solar

48 energy storage [19].

49 Previous research has demonstrated the utility of zeolites in high-temperature environments, 50 such as catalyzed reduction on $\mathrm{NO}_{\mathrm{x}}$ emissions from combustion to fossil fuels at temperature

51 up to $600{ }^{\circ} \mathrm{C}[12]$ and catalytic conversion of methane to desired chemical products or liquid

52 fuels [13]. These studies indicate the high thermal stability of zeolite, which derives from their

53 specific porous structures and silicon/aluminum ratios [20-22], but they do not illuminate the

54 upper limit for zeolite functionality, or provide insight into the mechanism by which zeolites

55 ultimately degrade and fail.

56 ZSM-5 is a zeolite which consists of 10 membered ring openings [23, 24]. The porous

57 framework of ZSM-5 accounts for its high specific surface area and makes it an interesting

58 material for gas adsorption [25]. Furthermore, compared to Y-type zeolites, ZSM-5 has an

59 exceptionally high degree of thermal stability due to its high silicon/aluminum ratio and pore

60 structure; it is therefore, potentially useful for processes involving elevated temperatures [20-

$6122]$.

62 ZSM-5 zeolites can also be used in intimate contact with a hydrogenating component such as

63 tungsten, vanadium, molybdenum, rhenium, nickel, cobalt, chromium, manganese, platinum or

64 palladium [20]. Previously, it has been shown that the presence of rare earth cations in Y-type

65 zeolites elevates the temperature at which the structure collapses [26].

66 In this work, zeolites are studied to determine if these materials are candidates for helium

67 uptake after exposure to high temperatures. The physical properties of ZSM-5 zeolite and 
samples loaded with platinum are characterized as a function of temperature up to $1500{ }^{\circ} \mathrm{C}$. To understand the structural evolution of the thermally treated zeolites, we employ X-ray

70 diffraction (XRD), scanning electronic microscopy (SEM), thermogravimetric analysis (TGA),

71 differential scanning calorimetry (DSC) and gas adsorption using the BET method. Comparing

72 these results we can then establish an activation energy for the mechanism (or mechanisms)

73 responsible for thermal degradation.

74

75

76

77

78

79

80

81

82

83

84

85

86

87

88

89

\section{EXPERIMENTAL METHODOLOGY}

\subsection{Materials}

Commercial zeolite, $\mathrm{NH}_{4}-\mathrm{ZSM}-5$ (CBV2314), was obtained from Zeolite International (Conshohocken, PA). In addition, platinum loaded samples of ZSM-5 were prepared by Makel Engineering Inc. (Chico, CA). We chose the platinum loaded samples to determine if these had better thermal stability. The ZSM-5 ions in solution were exchanged with a Pt ions in a 9-11 wt\% aqueous platinum solution of tetra ammine platinum (II) chloride hydrate $\left(\mathrm{Pt}\left(\mathrm{NH}_{3}\right)_{4} \mathrm{Cl}_{2} \times \mathrm{H}_{2} \mathrm{O}\right)$ obtained from Alfa Aesar. The mass ratio of zeolite to solution was 1.35 . The sample loaded with $\mathrm{Pt}$ is referenced here as Pt-ZSM-5. The procedure for platinum loading consisted of four steps. First, the ZSM-5 zeolite was dried at $100{ }^{\circ} \mathrm{C}$ for $4 \mathrm{~h}$. Second, the dried zeolite was weighed and then allowed to undergo ion exchange with the appropriate amount of aqueous platinum solution in a beaker mixed by a magnetic stir bar for $24 \mathrm{~h}$ at room temperature. Third, the resulting powder was filtered, rinsed with distilled water and calcined in air at $300{ }^{\circ} \mathrm{C}$ for $3 \mathrm{~h}$. Finally, the calcined product was reduced in a $10 \%$ hydrogen gas (balance nitrogen) flowing (500 sccm) at $450{ }^{\circ} \mathrm{C}$ for $6 \mathrm{~h}$. 


\subsection{X-ray Diffraction}

A Bruker-AXS D8 Advance diffractometer (Bruker-AXS, Inc.) operated at an accelerating voltage of $40 \mathrm{kV}$ and an emission current of $40 \mathrm{~mA}$ with CuKa $(\lambda=0.15406 \mathrm{~nm})$ was used to collect XRD powder patterns for the samples. XRD patterns were collected between $2 \theta$ angles of 5 to $60^{\circ}$ with a step size of $0.02^{\circ}$. Samples were mounted on zero-background holders.

\subsection{Electronic Microscopy (SEM) and Energy Dispersive X-Ray Spectroscopy (EDS)}

The zeolites were analyzed using SEM/EDS to determine particle size and to determine Si/Al atomic ratios. To facilitate SEM characterization, the zeolites powder were lightly ground and dusted onto double-sided carbon tape, then sputter-coated with Au-Pd for two minutes to improve the conductivity. The coating was performed with a plasma sputtering coater Denton Vacuum Desk II. Images were captured at different magnifications with a Philips XL30 SFEG SEM at $5 \mathrm{~kW}$ using a thermo-luminescent detector (TLD) detector. EDS measurements were taken at $5 \mathrm{~kW}$ electron beam accelerating power.

\subsection{Adsorption Experiments}

Gas adsorption measurements commonly determine the adsorption isotherm, the surface area and pore size distribution of many porous materials, such as industrial adsorbents, catalysts, pigments, and ceramics $[27,28]$. To determinate the adsorption isotherm, the surface area and the pore size, experiments were conducted with a Micromeritics Gemini VII 2390 surface area analyzer. Samples (15-20 mg) were pretreated to remove adsorbed contaminants from 
113 atmospheric exposure to air by degassing under vacuum at $400{ }^{\circ} \mathrm{C}$ for at least $12 \mathrm{~h}$ with a

114 Micromeritics VacPrep 061.

115 The surface area and pore size distribution were determined using nitrogen as the adsorptive 116 gas. Samples were cooled, under vacuum, at $77 \mathrm{~K}$. Then nitrogen was introduced to the sample

117 in controlled, incremental amounts. After each application of the adsorptive gas, the pressure 118 was allowed to equilibrate and the quantity of gas adsorbed on the sample was calculated from 119 the measured pressure. The gas volume adsorbed at each pressure at constant temperature 120 gives the adsorption isotherm. The method of Brunauer, Emmett, and Teller (BET) was 121 employed to determine the surface area [29], using a Micromeretics Gemini VII surface area 122 analyzer. In addition to nitrogen adsorption at $77 \mathrm{~K}$, the adsorption of nitrogen and the noble 123 gases helium and argon was measured at room temperature, $23{ }^{\circ} \mathrm{C}$.

$124 \quad$ 2.5. Differential Scanning Calorimetry and Thermogravimetric Analysis.

125

126 The thermal stability of the zeolites was studied using differential scanning calorimetry/thermal 127 gravimetric analysis (DSC/TGA). DSC and TGA analyses were acquired simultaneously on a 128 Setaram Setsys Evolution 1750 DSC/TGA Analyzer. All samples were run as powders in alumina 129 crucibles under synthetic air atmosphere (1 atm) at a heating rate of $10 \mathrm{~K} / \mathrm{min}$ from room 130 temperature up to $1500{ }^{\circ} \mathrm{C}$. The temperature was then decreased to room temperature at a 131 rate of $20 \mathrm{~K} / \mathrm{min}$.

132 2.6. Heat Treatment

133 Zeolite samples were treated at high temperatures to observe and characterized their thermal 134 degradation. Two different heat treatments were conducted. First, both zeolites, ZSM-5 and Pt- 
135 ZSM-5, were each heated to 800,1200 and $1500{ }^{\circ} \mathrm{C}$. These temperatures were selected from 136 our DSC/TGA results, as reported below in Section 3.2. Samples were heated in the presence of 137 air (1 atm) at a rate of $10{ }^{\circ} \mathrm{C} / \mathrm{min}$ to the target temperature using the Setaram Setsys Evolution $1381750 \mathrm{DSC} / \mathrm{TGA}$ Analyzer. The airflow rate was $20 \mathrm{~mL} / \mathrm{min}$. Once the samples achieved the 139 desired temperature, the samples were cooled at a rate of $20^{\circ} \mathrm{C} / \mathrm{min}$ to room temperature.

140 A second heat treatment was used to develop a model for the degradation of the Pt-ZSM-5. To 141 observe exclusively thermal surface area degradation, the heat treatment was performed in a 142 presence of nitrogen ambient. This avoids any chemical reactions such as oxidation that would 143 occur in air. Zeolite samples were exposed to temperatures of 950, 1000, 1050, 1100 and 1150

$144{ }^{\circ} \mathrm{C}$ under a nitrogen atmosphere for $2 \mathrm{~h}$. The temperature was increased at a constant rate of 10 $145{ }^{\circ} \mathrm{C} / \mathrm{min}$ to $800{ }^{\circ} \mathrm{C}$ and at a constant rate of $5{ }^{\circ} \mathrm{C} / \mathrm{min}$ above $800{ }^{\circ} \mathrm{C}$. The samples were heated in 146 an alumina tube furnace GSL 1700X-60 from MTI Corporation.

147

148

149

150

151

152

153 154 155 156 157

\section{RESULTS AND DISCUSSIONS}

\subsection{Characterization of Zeolites before Heat-Treatment}

Figure 1 shows the X-ray diffraction (XRD) patterns of zeolites. The zeolites have the typical patterns of the ZSM-5 structure [30-32], in agreement with Powder Diffraction File No \#440024 , with $2 \theta$ at $14.8^{\circ}, 23.27^{\circ}, 23.86^{\circ}, 24.58^{\circ}, 29.46^{\circ}, 30.31^{\circ}$, and $45.63^{\circ}$ corresponding to the major peaks of (301), (501), (422), (313), (532), (616), and (1000). The diffraction pattern of Pt-ZSM-5 shows that the crystal structure of the zeolite is maintained after platinum loading. The XRD reflection of Pt particles is observed in a new peak which does not exist for the ZSM-5 zeolite at $2 \theta=39.98^{\circ}$. This peak corresponds to (111) for platinum [Powder Diffraction File No 
158

159

160

161

\#70-2431] [33, 34]. Since metallic Pt has an atomic diameter of $2.7 \AA$, large Pt crystals cannot form inside the channels. However, Pt crystals could form on the outside surface of the zeolite particles.

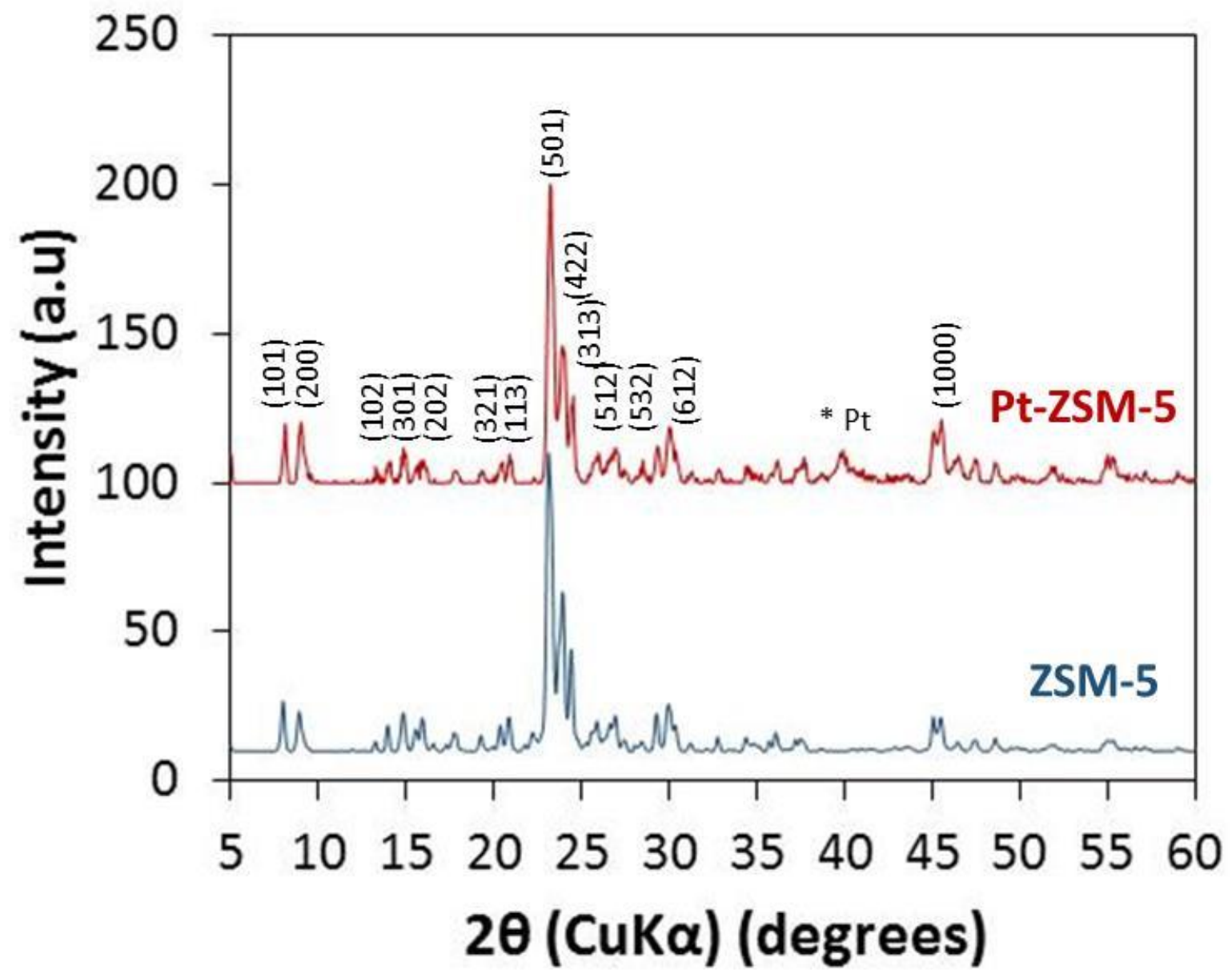

Figure 1: XRD patterns of ZSM-5 and Pt-ZSM-5. The location of the Pt peak is indicated on the figure.

Figure 2 shows representative SEM images for the ZSM-5 zeolite sample. Particles are irregularly shaped, with smaller particles having largest dimension of $\sim 100 \mathrm{~nm}$; larger particles have largest dimensions of a few hundred $\mathrm{nm}$. From the EDS results shown in the Table 1 , the zeolites are primarily composed of $\mathrm{Si}$ and $\mathrm{Al}$, as expected. The Si/Al atomic ratio is 22 
167 (calculated from the EDS results) for ZSM-5, close to the ratio of 23 reported by Zeolyst 168 International.
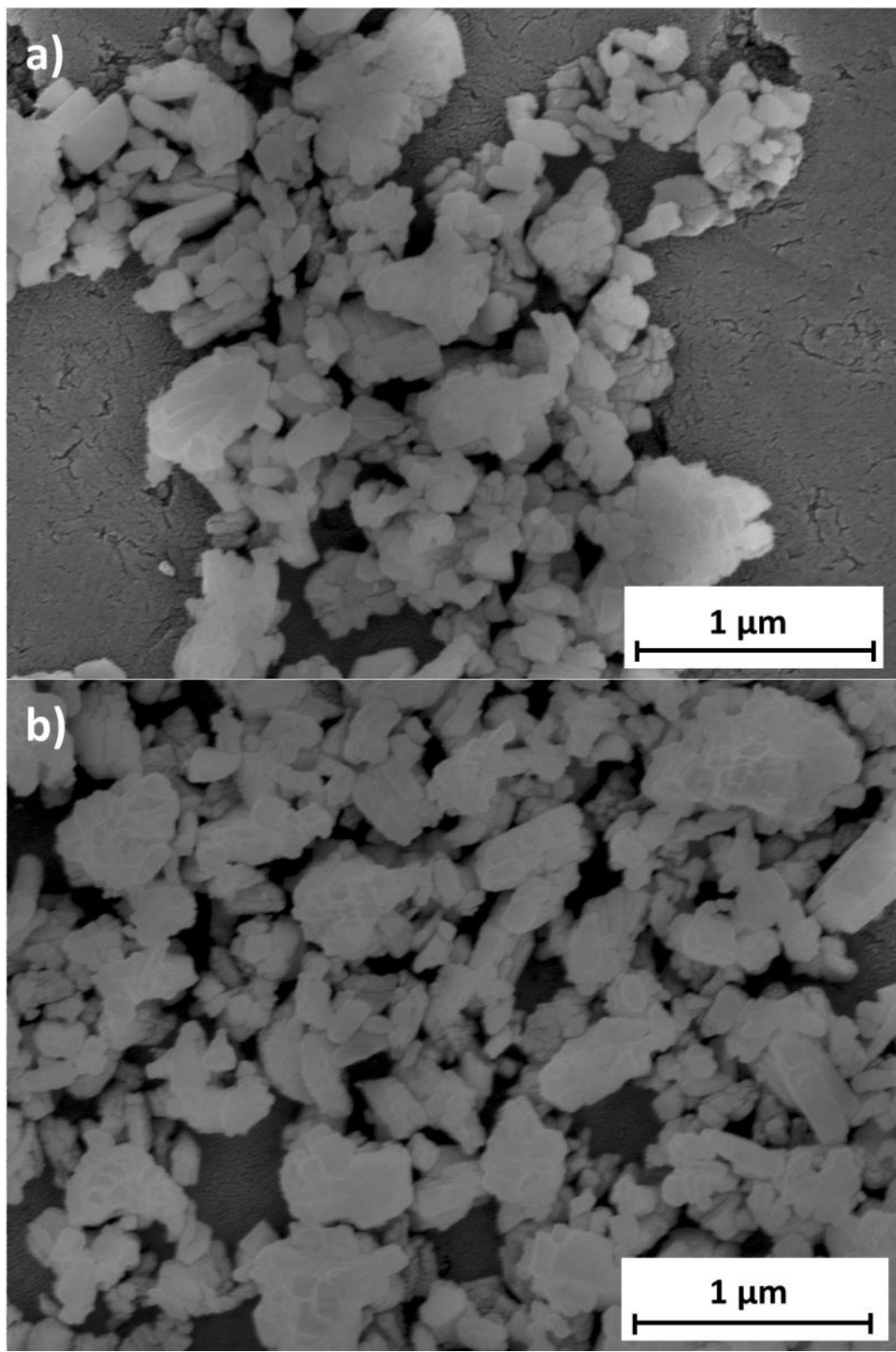

Figure 2: Zeolite ZSM-5 SEM pictures take at $5 \mathrm{kV}$ and $65 \mathrm{Kx}$.

Table 1: EDS results of ZSM-5

\begin{tabular}{cc}
\hline Element & ZSM-5 \\
\hline$O$ (at\%) & $47.4 \pm 10.59$ \\
Al (at\%) & $2.24 \pm 0.66$ \\
Si (at\%) & $50.36 \pm 14.05$
\end{tabular}


170 The nitrogen adsorption isotherms of zeolites ZSM-5 and Pt-ZSM-5 are shown in Fig. 3. The

171 features of the isotherms indicate only filling of micropores and no presence of mesopores. The

172 isotherms show high nitrogen uptakes at low relative pressure and a plateau at high relative

173 pressure, typical from the microporous materials. The sub-step observed around P/Po 0.2 in the

174 isotherm is a typical feature of MFI type zeolites and is associated with a fluid-to-solid-like

175 phase transition of the adsorbed nitrogen in microporous network [27]. The two isotherms are

176 similar, however the ZSM-5 isotherm shows a higher quantity of adsorbed nitrogen. This may

177 be due to a partial blockage of nitrogen by Pt atomic clusters or due to Pt atoms occupying

178 adsorption sites inside the zeolite channels.

179 Adsorption isotherms data can be used for characterizing the gas adsorption properties of 180 porous materials $[31,32,35,36]$ and are used to obtain specific surface areas. The use of the 181 calculated surface area is controversial for microporous media [37-40], however the practice is 182 widespread. Here, we use the specific surface area solely as comparative measure for analyzing 183 the effects of thermal treatments of the zeolites. The surface areas obtained are given in Table 1842 and ZSM-5 gives the highest specific surface area. 


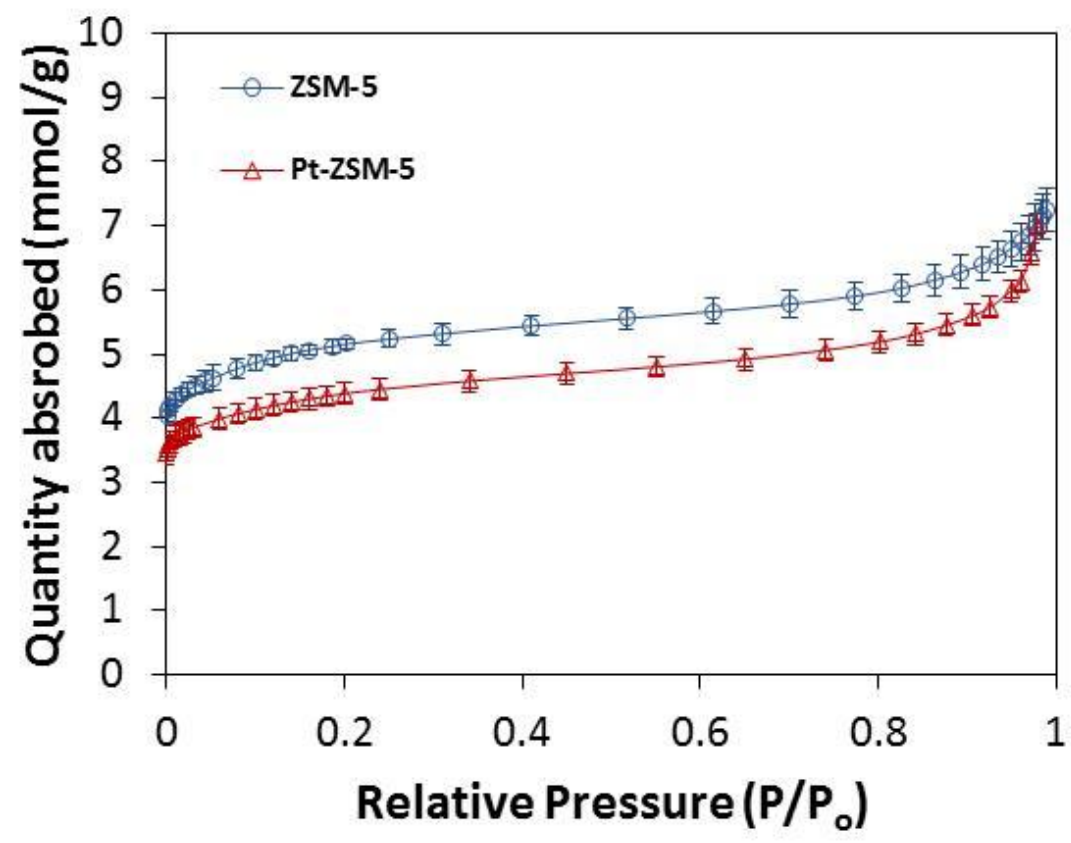

Figure 3: Nitrogen adsorption isotherms of ZSM-5 and Pt-ZSM-5 at $77 \mathrm{~K}$.

Table 2: Specific surface area for ZSM-5, Pt-ZSM-5.

\begin{tabular}{c|c}
\hline Zeolite & Specific Surface Area $\left(\mathrm{m}^{2} / \mathrm{g}\right)$ \\
\hline ZSM-5 & $410 \pm 5$ \\
Pt-ZSM-5 & $386 \pm 1$ \\
\hline
\end{tabular}

188

\subsection{Thermal Degradation of Zeolites}

190 Thermal stability is the resistance that a material has to decomposition at high temperatures.

191 To study the thermal stability of zeolites, TGA and DSC were carried out on the zeolite samples

192 following the protocol described in the experimental methodology section 2.6. Figures 4 and 5

193 show the TGA/DSC profiles of the zeolites in air up to $1500^{\circ} \mathrm{C}$. One can observe that there is an

194 endothermic peak between 100 and $250{ }^{\circ} \mathrm{C}$, which is due to loss of water of hydration from the

195 pores. From the TG profile in this range of temperatures, the weight decreases up to $250{ }^{\circ} \mathrm{C}$,

196 then, the loss of weight is more gradual up to $1000{ }^{\circ} \mathrm{C}$ and then is stable from 1000 to $1500{ }^{\circ} \mathrm{C}$. 
197 The total lost mass is 7.5\% for ZSM-5 and $6.5 \%$ for Pt-ZSM-5 over the total temperature range.

198 About $75 \%$ of the total weight loss occurs from 0 and $250{ }^{\circ} \mathrm{C}$ due to removal of the water of 199 hydration [30, 41, 42]. Figure 4 shows a large exothermic peak centered at about $1200{ }^{\circ} \mathrm{C}$ for 200 the ZSM-5 zeolite, which is likely attributed to a phase transition since at that point the porous 201 structure of zeolite has collapsed [20]. Note that there is not a corresponding change in mass, 202 consistent with crystallization. A small shoulder is observed at about $1000{ }^{\circ} \mathrm{C}$, suggesting the 203 process occurs in two steps. Figure 5 clearly shows two smaller exothermic peaks for Pt-ZMS-5, 204 the smallest at around $920{ }^{\circ} \mathrm{C}$, probably due to the local collapse of the porous structure, 205 followed by a larger peak at $1200{ }^{\circ} \mathrm{C}$ due to crystallization. Both peaks at $1200{ }^{\circ} \mathrm{C}$ in Figs. 4 and 5 206 are attributed to crystallization of a new phase, likely cristobalite .

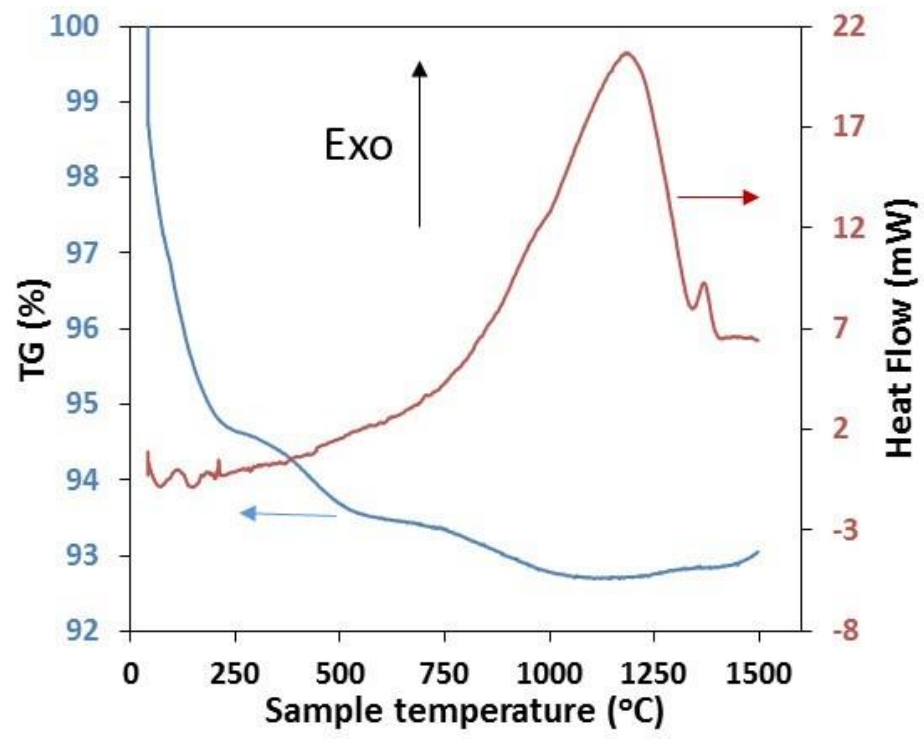

Figure 4: TGA/DSC profiles of ZMS-5 zeolite in air to $1500^{\circ} \mathrm{C}$ 


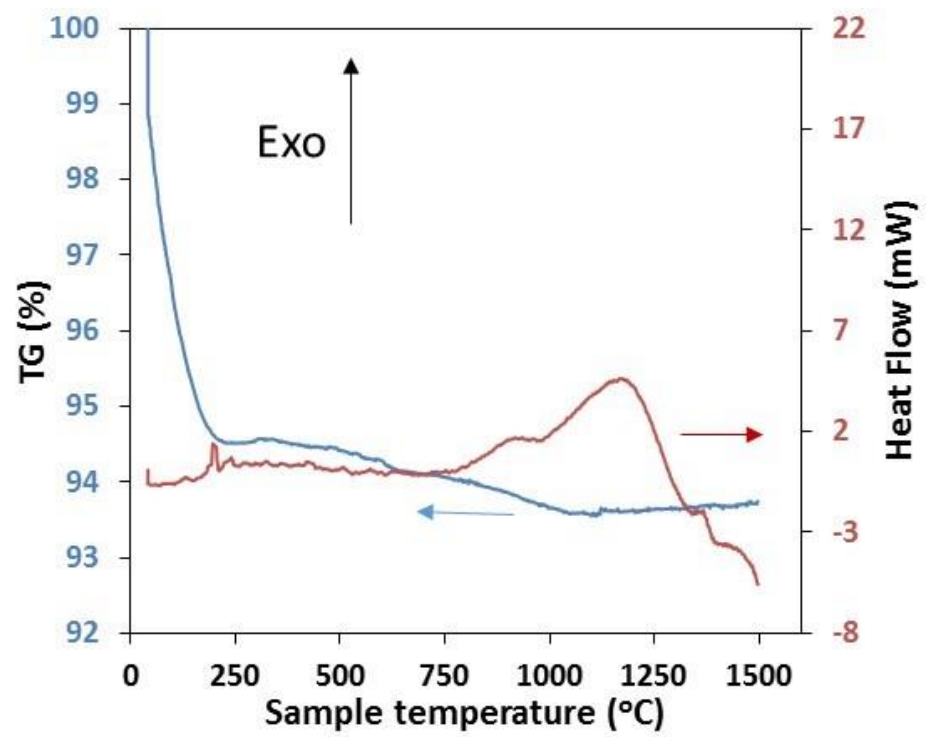

207

Figure 5: TGA/DSC profiles of Pt-ZMS-5 zeolite in air to $1500^{\circ} \mathrm{C}$.

208 Comparing Figs. 4 and 5 the exothermal heat flow of ZSM-5 is larger than that of Pt-ZSM-5. The

209 ZSM-5 exothermic heat flow begins with the shoulder at about $500{ }^{\circ} \mathrm{C}$ and then begins to grow

210 at about $750{ }^{\circ} \mathrm{C}$ while in the Pt-loaded zeolite the second exothermic peak begins at $950{ }^{\circ} \mathrm{C}$. This

211 small difference between the thermal signature of the modified zeolite versus the original

212 zeolite may be due to Pt hindering diffusion of the components, retarding phase transition

213 kinetics and may indicate a somewhat improved thermal stability compared to ZSM-5.

214 It has been reported that ZSM-5 is thermally stable to $930{ }^{\circ} \mathrm{C}[20,21]$. Since the DSC/TGA 215 results indicate changes in the structure starting around $920{ }^{\circ} \mathrm{C}$, XRD experiments were 216 performed to determine if there are phase transitions for the zeolites when they are heated up 217 to $1500{ }^{\circ} \mathrm{C}$. Figures 6 and 7 show the XRD patterns for the zeolites ZSM-5 and Pt-ZSM-5 heated 218 to 800,1200 and $1500{ }^{\circ} \mathrm{C}$, respectively. The XRD results show that the intensities of the main 219 spectrum peaks, (501), (422), and (311) (Fig. 1) decrease from 800 to $1200{ }^{\circ} \mathrm{C}$. However, Fig. 7 220 shows that the peak that corresponds to platinum ( $2 \theta$ at about $40^{\circ}$ ) increases, and a new peak 
221 at $46.37^{\circ}$ appears for temperatures between 800 and $1200{ }^{\circ} \mathrm{C}[33,34]$. This new peak also 222 corresponds to (200) planes and suggests that Pt is starting to coarsen into larger particles as 223 the structure crystallizes.

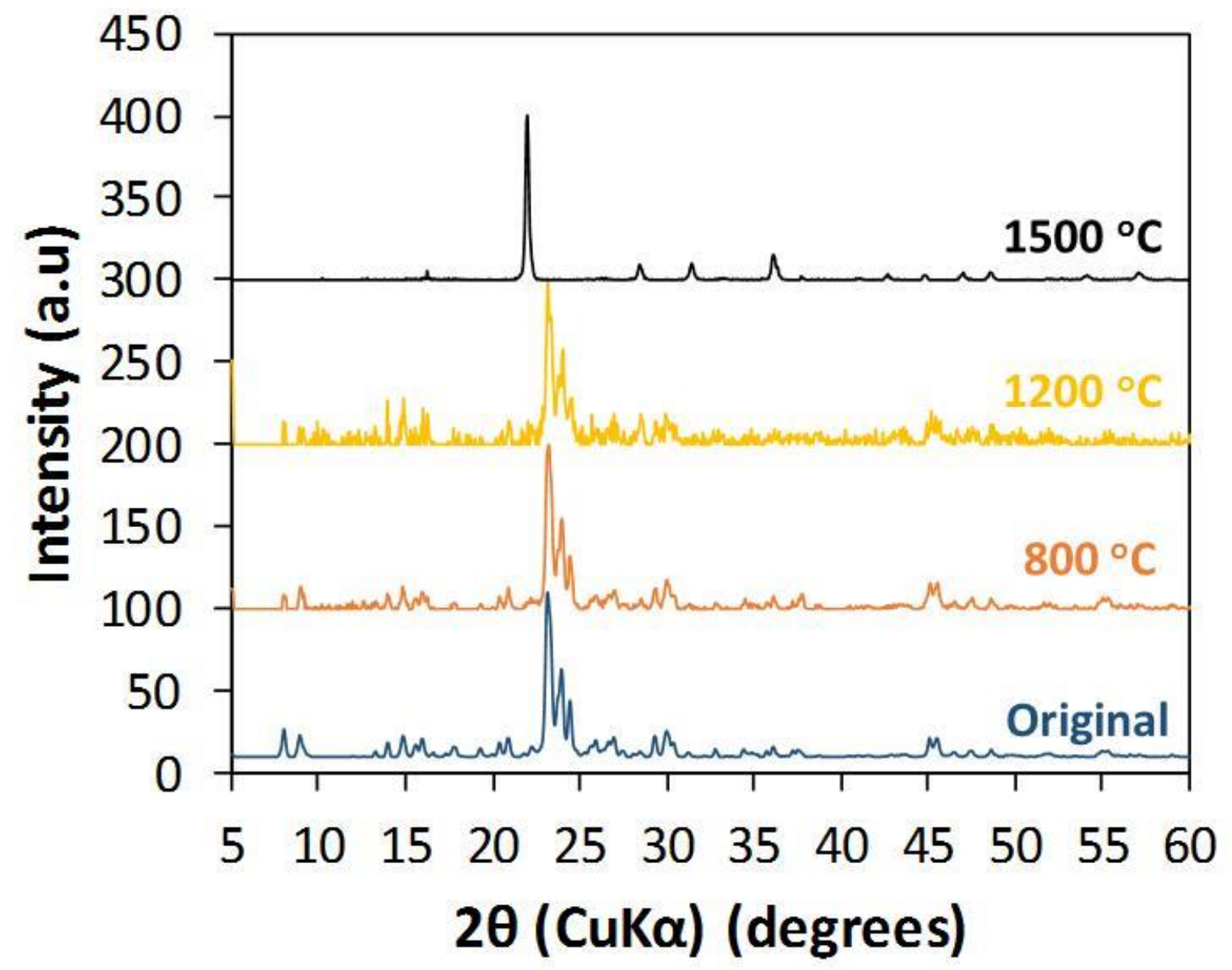

Figure 6: XRD patterns at room temperature for ZSM-5 heated to 800,1200 , or $1500{ }^{\circ} \mathrm{C}$ compared with the original ZSM-5 sample at room temperature. 


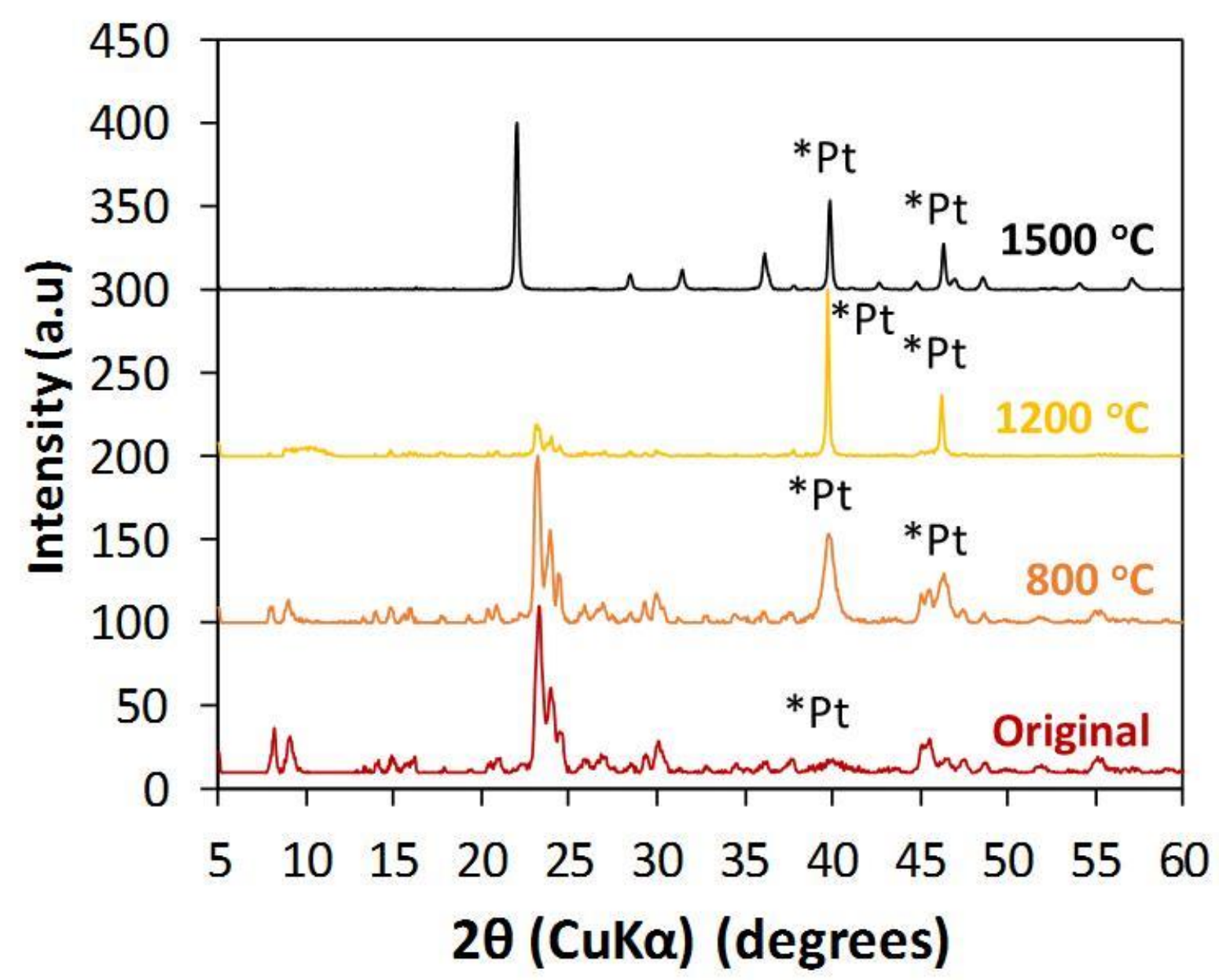

Figure 7: XRD patterns at room temperature for Pt-ZSM- heated to 800,1200 , and $1500{ }^{\circ} \mathrm{C}$ compared with the original Pt-ZSM-5 sample at room temperature.

225 When the thermal treatment is at $1500{ }^{\circ} \mathrm{C}$, the typical peaks of ZSM-5 disappear and new ones, 226 corresponding to a cristobalite-like structure (Powder Diffraction File No \#77-1316), appear.

227 Note that cristobalite is composed of $\mathrm{SiO}_{2}$; however the zeolite is composed also of alumina. In 228 order to determine if the alumina is still present in the zeolites after the heat treatment at 1500 $229{ }^{\circ} \mathrm{C}$, EDS experiments were performed. Curiously, at $1200{ }^{\circ} \mathrm{C}$ the ZSM-5 appears to still retain a 230 diffraction pattern similar to the original, but Pt-ZSM-5 has significant changes at $1200{ }^{\circ} \mathrm{C}$.

231 Table 3 shows the Si/Al ratio of the two zeolites after the heat treatment at $1500{ }^{\circ} \mathrm{C}$. 
Table 3: $\mathrm{Si} / \mathrm{Al}$ atomic ratios of zeolites after heat treatment at $1500{ }^{\circ} \mathrm{C}$ compared with the ratios obtained for the zeolites before the heat treatment.

\begin{tabular}{c|c|c}
\hline Zeolite & Si/Al ratio $\left(1500{ }^{\circ} \mathrm{C}\right)$ & Si/Al ratio (as made) \\
\hline ZSM-5 & $13.8 \pm 0.4$ & $11.5 \pm 0.3$ \\
Pt-ZSM-5 & $14.4 \pm 0.3$ & $12.4 \pm 0.6$ \\
\hline
\end{tabular}

235

$236 \mathrm{Si} / \mathrm{Al}$ ratios obtained for ZSM-5 and Pt-ZSM-5 after the heat treatment are slightly higher to the $237 \mathrm{Si} / \mathrm{Al}$ ratios obtained in the zeolites before the heat treatments (see section 3.1 and Table 3 )

238 indicating only a small loss of alumina. Thus the EDS results show that alumina is still present in 239 the zeolites after the heat treatment and the results are supported by the DSC/TGA data, which 240 only show a small mass reduction. The XRD spectra at $1500{ }^{\circ} \mathrm{C}$ show a cristobalite structure 241 which is composed only by $\mathrm{SiO}_{2}$, which suggests that alumina may have changed into a 242 completely amorphous structure which cannot be observed by XRD.

243 Figure 8 shows SEM pictures of different zones of the ZSM-5 sample heat treated up to $1500{ }^{\circ} \mathrm{C}$. 244 Images were taken at different magnifications. Individual particles of ZSM-5 can be observed in 245 Figures 8 b) and $8 \mathrm{~d}$ ). These particles are similar to the particles that can be observed in the 246 SEM images of ZSM-5 without any heat treatment (Fig. 2). However, other zones of the samples 247 show that particles are more agglomerated and the images show bigger particles than in the 248 original sample. This means that during the heat treatment, individual particles were sintered 249 together as shown in Figure 8 c) via liquid phase sintering, commonly present in aluminosilicate 250 systems. 


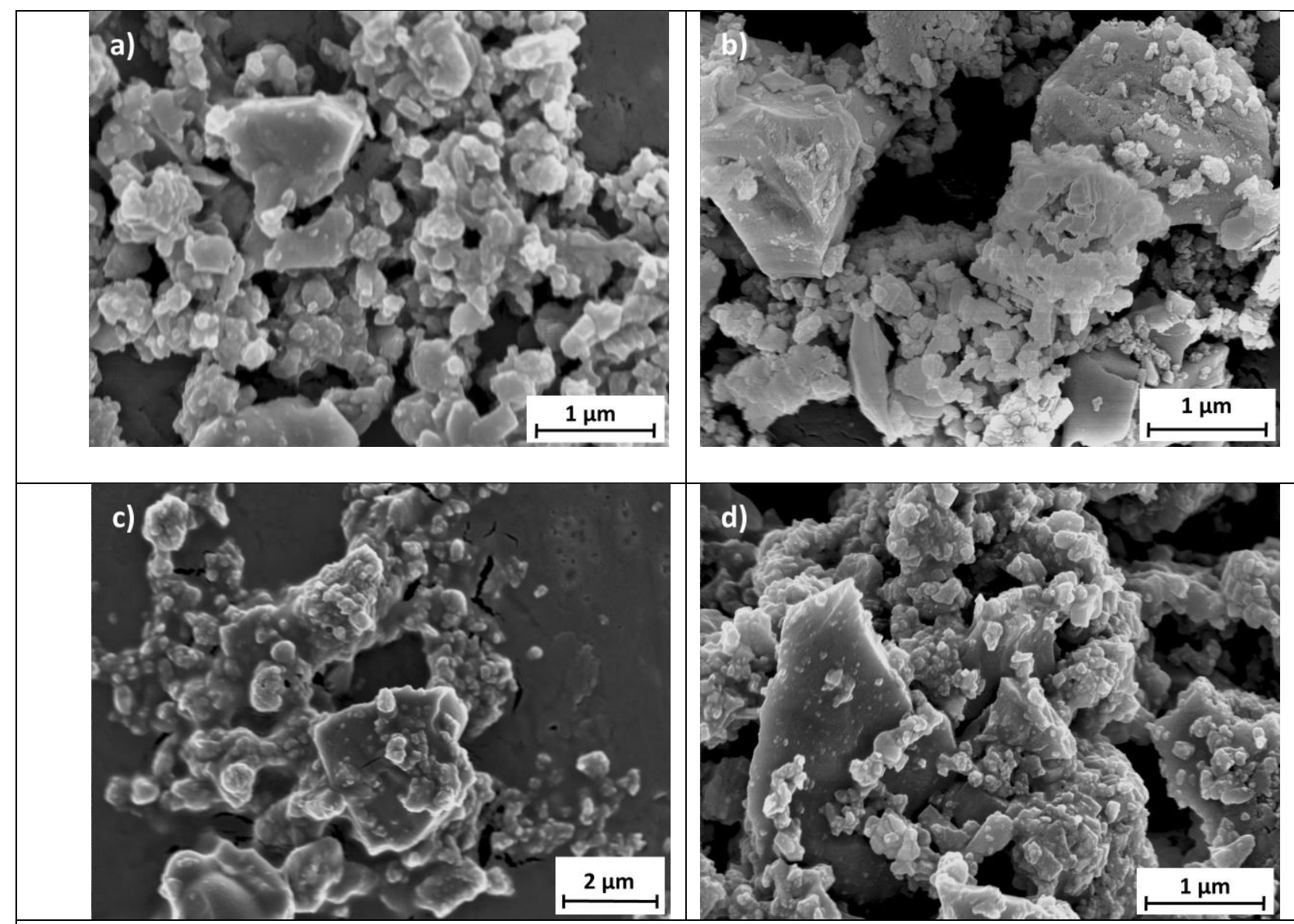

Figure 8: Zeolite ZSM- 5 heat treated at $1500{ }^{\circ} \mathrm{C}$ pictures taken at $5 \mathrm{~kW}$ at different magnifications. a), b) and d) images taken at $25 \mathrm{Kx}$ is $1 \mu \mathrm{m}$. Image c) taken at $10 \mathrm{Kx}$, the bar is $2 \mu \mathrm{m}$.

\subsection{Effect of the temperature in the nitrogen adsorption isotherms and surface area at 77} K.

255 The decomposition of the zeolite samples has been characterized by gas adsorption

256 measurements. Temperatures were selected corresponding to the peaks on the DSC profiles,

257 i.e., $800{ }^{\circ} \mathrm{C}$ and $1200{ }^{\circ} \mathrm{C}$. In addition, zeolites samples were heated to $1500{ }^{\circ} \mathrm{C}$. The heat 258 treatment was carried out in air as described by the procedure given in the experimental 259 section. The adsorptive properties and the composition of each zeolite are reported below. 
260 The nitrogen adsorption isotherms of the zeolites after heat treatment in air to 800 and 1200

$261{ }^{\circ} \mathrm{C}$, respectively, are shown in Figs. 9 and 10. The error bars, based on two standard deviations, 262 indicate that the gas adsorption properties of ZSM-5 and Pt-ZSM-5 are similar within the margin

263 of error. A small difference is observed in the Pt-ZSM-5 isotherm. Interestingly, the adsorption

264 isotherms at $800{ }^{\circ} \mathrm{C}$ are nearly identical to those observed for the untreated zeolites shown in

265 Fig. 3. These results indicate that the start of the exothermic heat flows observed by DSC at 750

266 and $800{ }^{\circ} \mathrm{C}$ (see Figs. 4 and 5) do not result in significant changes in the gas adsorption

267 properties and therefore the pore structures in the zeolites. However, comparisons between

268 the isotherms for the zeolites heat-treated to $800{ }^{\circ} \mathrm{C}$ (Fig. 9) with the isotherms for the zeolites

269 heat-treated to $1200{ }^{\circ} \mathrm{C}$ (Fig. 10) show a drastic reduction of the gas adsorption properties for

270 the samples treated to $1200{ }^{\circ} \mathrm{C}$. The exothermic peak at $1200{ }^{\circ} \mathrm{C}$ (Figs. 4 and 5) and the results

271 in Fig. 10 indicate significant changes in pore structure occurred in the pore volumes. These

272 changes are consistent with the XRD results. 


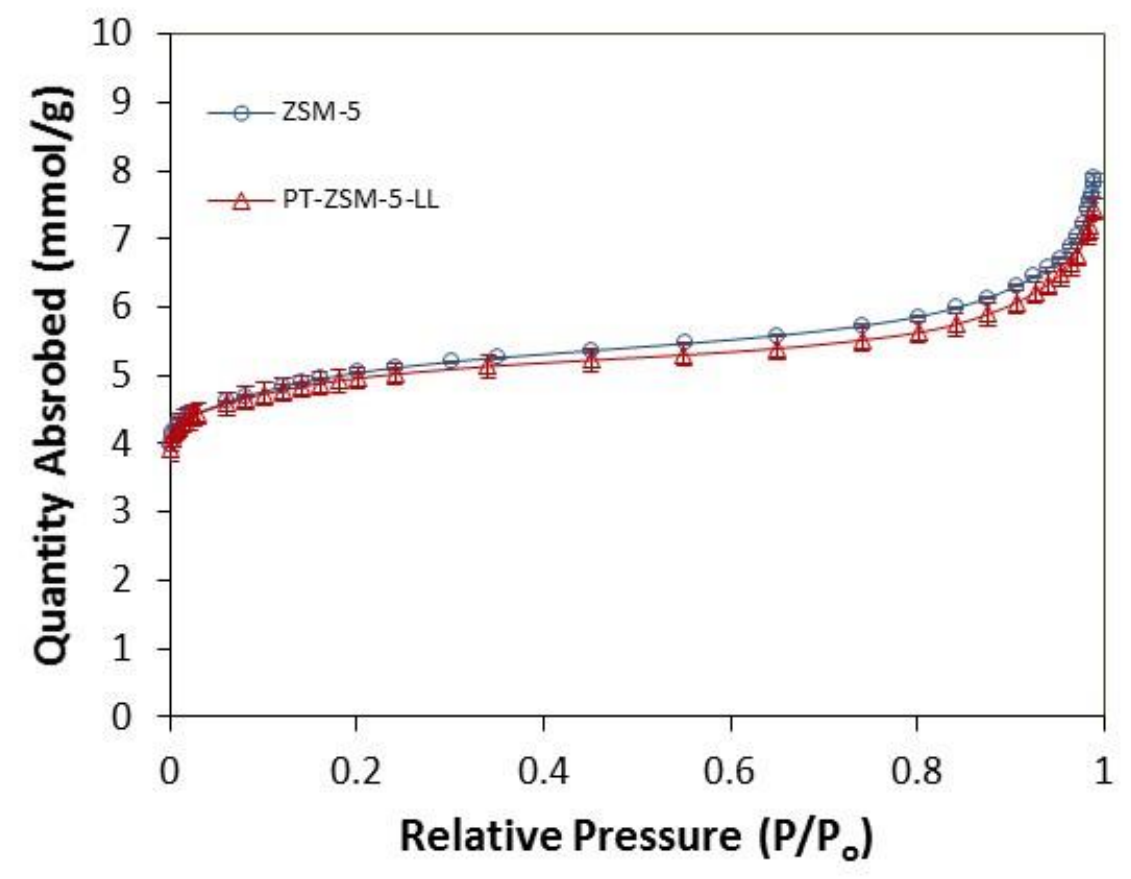

273

274

Figure 9: Nitrogen adsorption isotherms at $77 \mathrm{~K}$ for ZSM-5 and Pt-ZSM-5 heat-treated to $800{ }^{\circ} \mathrm{C}$.

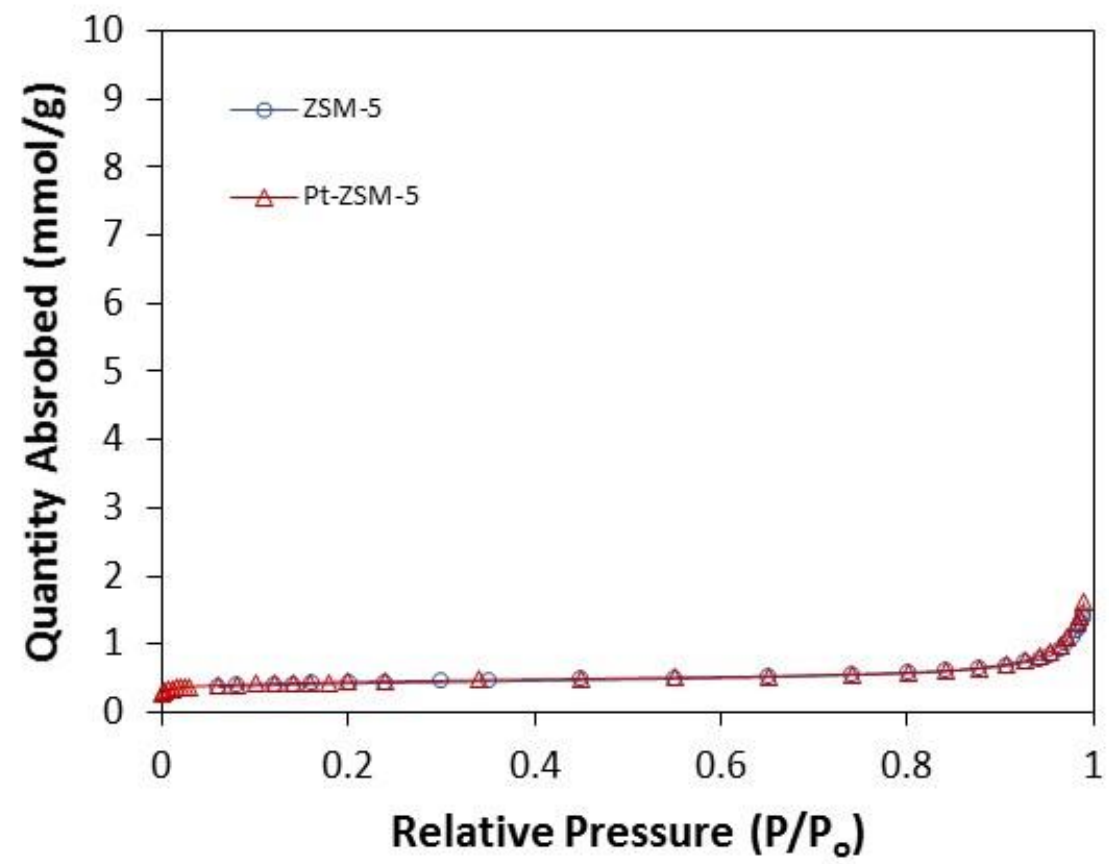

275

276 Figure 10: Nitrogen adsorption isotherms at $77 \mathrm{~K}$ for ZSM-5 and Pt-ZSM-5 heat-treated to $1200{ }^{\circ} \mathrm{C}$. 
277 Table 4 shows the specific surface areas of ZSM-5 and Pt-ZSM-5 at different temperatures. The

278 surface areas decrease when the heat treatment temperature increases. The specific surface

279 areas of the samples at $1500{ }^{\circ} \mathrm{C}$ are lowest for each zeolite, indicating that the porosity of the

280 sample is low, corresponding to a structural collapse, in agreement with the previous results

281 with DSC and the nitrogen adsorption isotherms.

282 The pore size distribution and the maximum pore volume measured at $\mathrm{P} / \mathrm{Po}=0.989$ for both

283 zeolites, ZSM-5 and Pt-ZSM-5, heat treated to different temperatures are represented in Table

284 5. The pore size distribution based on the nitrogen adsorption isotherms can be derived from

285 several methods. Methods are based on the micropores filling theory and on the interaction

286 potential between adsorbate and adsorbent such as the Horvath and Kawazoe (H-K) model,

287 which is a simple and popular model for evaluating pore size distribution of microporous

288 materials [16]. This technique is often used for the determination of the pore size distribution

289 in many micropores adsorbents such as activated carbon or zeolites.

290 The pore size distribution and the maximum pore volume remain about the same when the

291 temperature increases to $800{ }^{\circ} \mathrm{C}$. At $1200{ }^{\circ} \mathrm{C}$ the values are difficult to measure because they

292 are small and have large standard deviations.

294 Table 4: Surface areas of ZSM-5, and Pt-ZSM-5 heated to different temperatures. At $1500{ }^{\circ} \mathrm{C}$, the specific 295 surface areas of ZSM-5 and Pt-ZSM-5 are not measurable.

\begin{tabular}{c|c|c}
\hline Temperature $\left({ }^{\circ} \mathbf{C}\right)$ & \multicolumn{2}{|c}{ Specific surface area $\left(\mathbf{m}^{\mathbf{2}} \mathbf{/ g}\right)$} \\
\hline Room temperature & ZSM-5 & Pt-ZSM-5 \\
800 & $410 \pm 5$ & $386 \pm 1$ \\
1200 & $389 \pm 3$ & $399 \pm 1$ \\
& $35 \pm 3$ & $34 \pm 5$
\end{tabular}


297 Table 5: Pore size distribution and maximum pore volume of ZSM-5 and Pt-ZSM-5 heated to different 298 temperatures. At 1200 and $1500{ }^{\circ} \mathrm{C}$, the values of ZSM-5 and Pt-ZSM-5 too small or lead to large 299 standard deviations.

\begin{tabular}{c|c|c|c|c}
\hline Temperature $\left({ }^{\circ} \mathbf{C}\right)$ & \multicolumn{2}{|c|}{ Pore size distribution $(\mathbf{n m})$} & \multicolumn{2}{c}{ Maximum pore volume at P/P $\mathbf{P}_{\mathbf{o}}=\mathbf{0 . 9 8 9}\left(\mathbf{c m}^{\mathbf{3}} / \mathbf{g}\right)$} \\
\hline & ZSM-5 & Pt-ZSM-5 & ZSM-5 & Pt-ZSM-5 \\
\hline Room temperature & $0.64 \pm 0.26$ & $0.74 \pm 0.3$ & $0.25 \pm 0.003$ & $0.246 \pm 0.003$ \\
800 & $0.72 \pm 0.4$ & $0.73 \pm 0.5$ & $0.266 \pm 0.006$ & $0.255 \pm 0.007$ \\
1200 & - & - & $0.05 \pm 0.005$ & $0.055 \pm 0.008$ \\
1500 & - & - & - & - \\
\hline
\end{tabular}

\subsection{Comparison of the Adsorption of Helium, Argon and Nitrogen at Room Temperature}

301 Crystallization of zeolite at high temperatures decreases pore volume, and consequently, 302 adsorbed nitrogen. Furthermore, a constriction of the pores limits the entrance of nitrogen into 303 the pores. However, smaller gas atoms such as helium, could still enter if inter-atomic spacing 304 allows. Helium has a kinetic diameter of $2.6 \AA$ [43], while the unit cell of cristobalite, the 305 polymorph of silica observed after high-temperature treatment of zeolite, has a smallest lattice 306 constant dimension of $4.97 \AA$ [44].

307 The helium condensation temperature is $4 \mathrm{~K}$. This temperature presents a significant barrier to 308 performing gas adsorption measurements at the condensation temperature. To compare the 309 adsorption of different gases at the same conditions, adsorption studies at room temperature 310 using nitrogen, helium and argon were performed. Figures 11-14 show the helium, argon, and 311 nitrogen isotherms at room temperature of Pt-ZSM-5 without heat-treatment and with heat 312 treatments. 


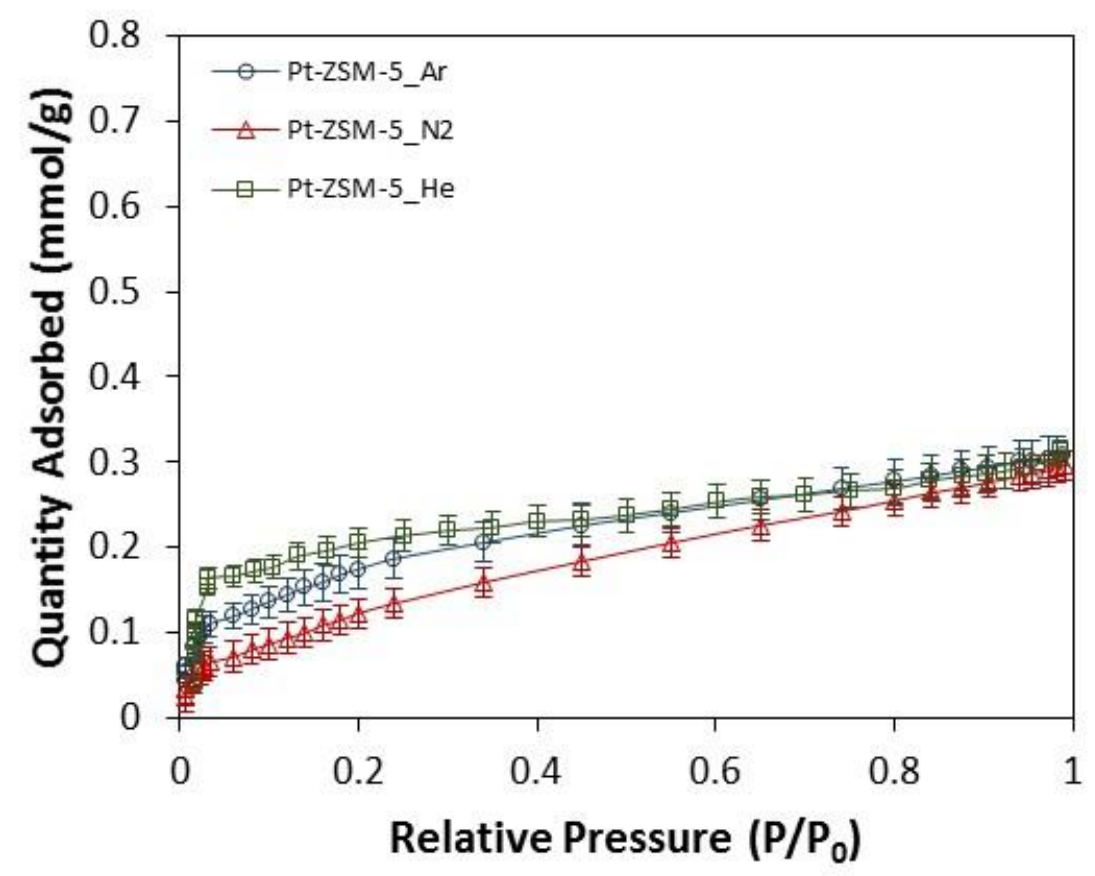

Figure 11: Argon, nitrogen and helium adsorption isotherms at room temperature for Pt-ZSM-5, not heat-treated.

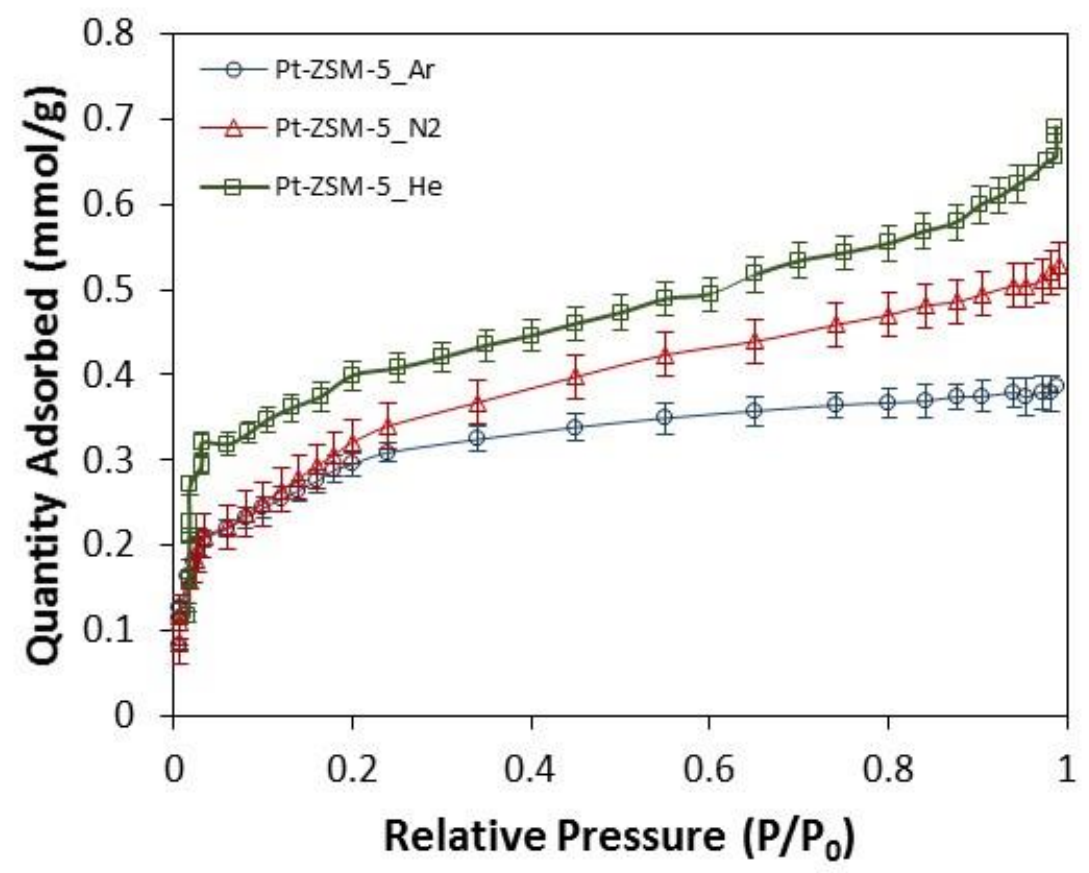

Figure 12: Argon, nitrogen and helium adsorption isotherms at room temperature of Pt-ZSM-5 heated to $800{ }^{\circ} \mathrm{C}$. 


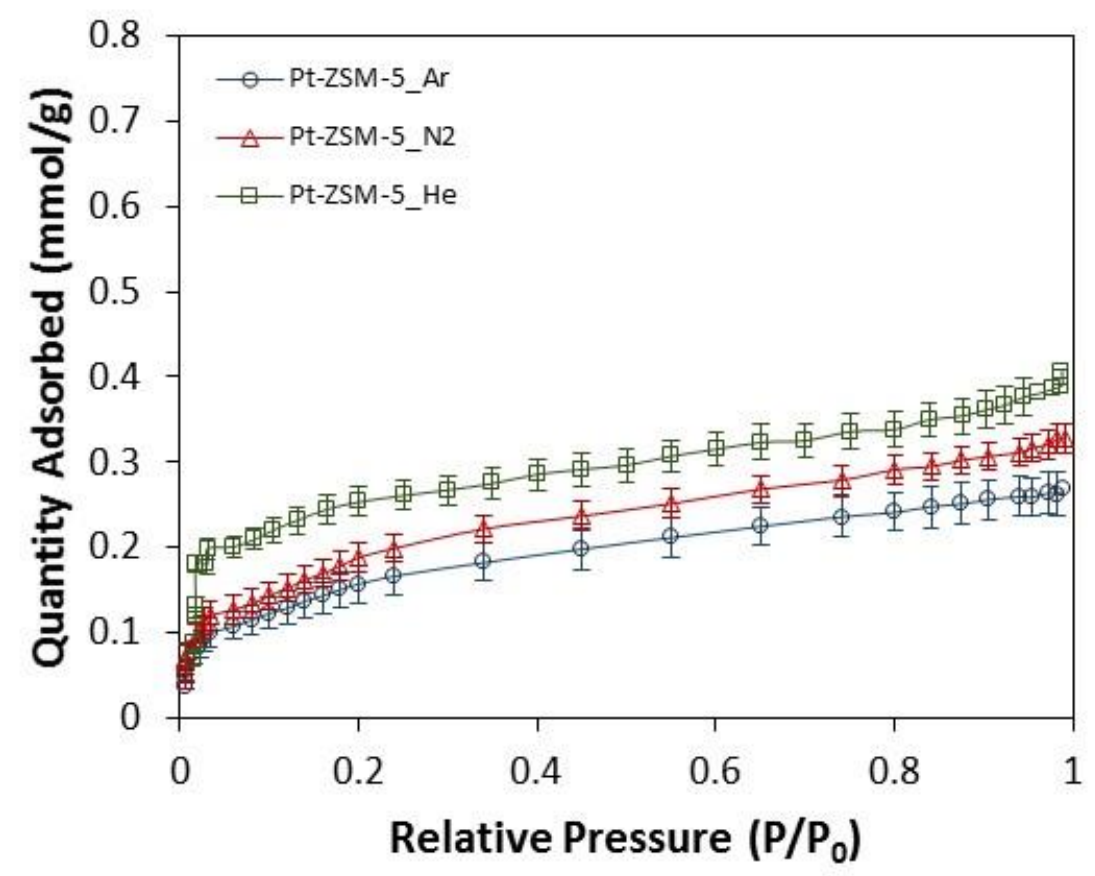

Figure 13: Argon, nitrogen and helium adsorption isotherms at room temperature of Pt-ZSM-5 heated to $1200{ }^{\circ} \mathrm{C}$.

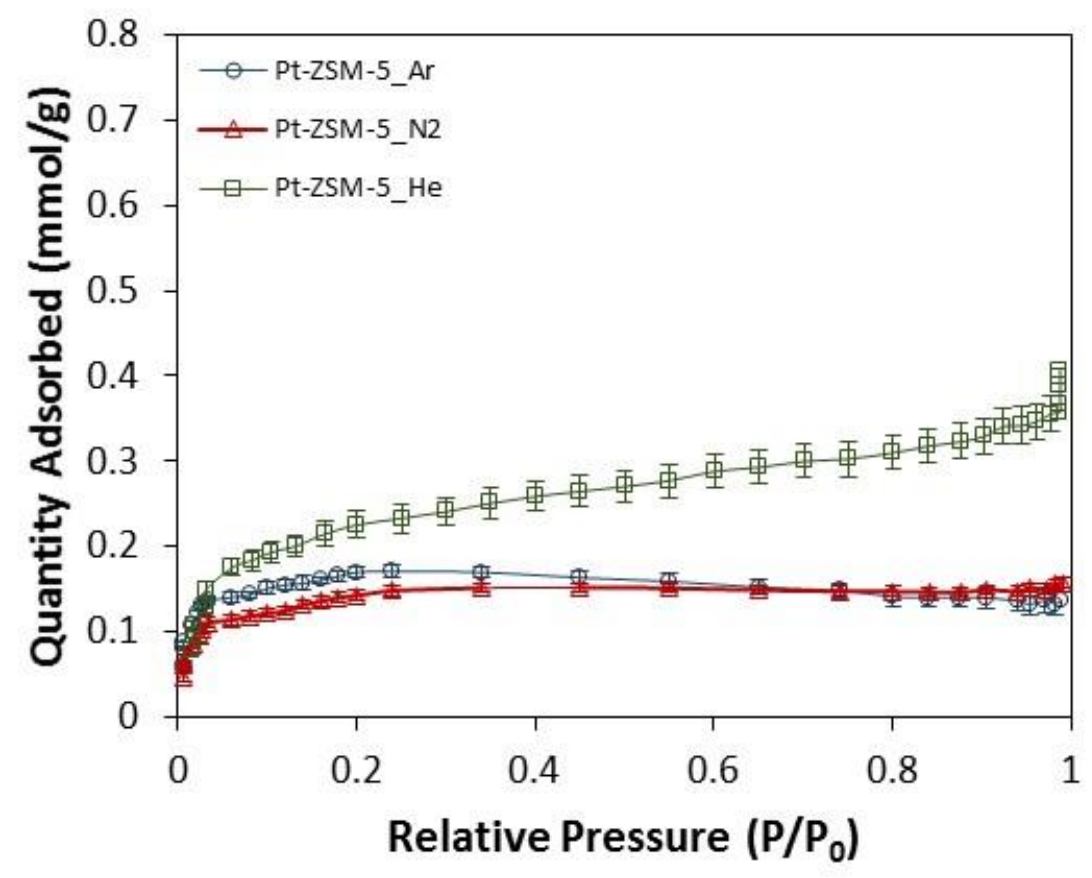

Figure 14: Argon, nitrogen and helium adsorption isotherms at room temperature of Pt-ZSM-5 heated to $1500{ }^{\circ} \mathrm{C}$. 
315 For the original Pt-ZSM-5, the three isotherms are shown in Fig. 11. There is virtually no 316 difference when the relative pressure approaches 1 . However, at lower relative pressures the 317 quantity of adsorbed helium is considerably higher than that of argon and nitrogen.

318 Figs. 12-14 show the isotherms for helium, nitrogen and argon at room temperature for Pt319 ZSM-5 heated to 800,1200 and $1500{ }^{\circ} \mathrm{C}$, respectively. One can observe that for the three 320 temperatures the quantity of adsorbed helium is considerably higher than the quantities for 321 argon and nitrogen. Argon has the lowest adsorption. Further, for the zeolite heated up to 800

$322{ }^{\circ} \mathrm{C}$, the quantity adsorbed is higher than for the original zeolite (Fig 11). The difference between 323 the isotherms becomes larger when the zeolite is heated to $1500{ }^{\circ} \mathrm{C}$, as seen in Fig. 14.

324 For the zeolite samples heated to $1500{ }^{\circ} \mathrm{C}$, the structure is different than at the lower 325 temperatures: a cristobalite-type structure has formed, the pores are completely collapsed and 326 the adsorption properties are decreased. However, the zeolites can still adsorb helium after the 327 heat treatment at $1500{ }^{\circ} \mathrm{C}$. Helium is the smallest molecule, so when the pores collapse, helium 328 still penetrates the densified material, as allowed by inter-atomic spacing.

\subsection{Degradation Model at High Temperatures.}

330 The degradation of zeolite Pt-ZSM-5 in nitrogen at high temperatures was studied. Five samples 331 were held for two hours at one of the following five temperatures: 950, 1000, 1050, 1100 and $3321150{ }^{\circ} \mathrm{C}$. Heating rates for this thermal treatment are described in Section 2.6. BET adsorption 333 studies at $77 \mathrm{~K}$ were carried out on each sample with the method described in the experimental 334 methodology. 
335 Figure 15 shows the relation between the apparent specific surface area and the treatment 336 temperature. Collapse of the pore structure and the degradation of the specific surface area 337 start at about 1025 and is complete at $1150{ }^{\circ} \mathrm{C}$. The behavior is similar to the results discussed 338 previously for samples heated in air. At lower temperatures the change in the specific surface 339 area is not significant, but the most significant change in the surface area is observed in the 340 temperature range of 1025 to $1100{ }^{\circ} \mathrm{C}$, which corresponds to the collapse of the porous 341 structure of ZSM-5. This behavior is consistent with the results for the DSC/TGA and adsorption 342 measurements presented previously.

343 The temperature dependence of the rate of decay for the specific surface area can be modeled 344 as an Arrhenius process as shown in Eq (1) [45]. The time derivative in Eq (1) was approximated 345 by dividing the change in specific surface area by the holding time of two hours described 346 previously.

$$
\frac{d A_{s p}}{d t}=k(T)=C \cdot e^{-\frac{E_{A}}{R \cdot T}}
$$

348 Equation (1) was linearized and fit via sum of least squares regression to find $E_{A}$ and $C$. The best 349 fit gave an activation energy, $E_{A}$, of $402 \mathrm{~kJ} / \mathrm{mole}$ with $\mathrm{C}$ equal to $-1.399 \cdot 1014 \mathrm{~m}^{2} /(\mathrm{g}-\mathrm{s})$ ????. 350 Simple integration of Eq (1) results in Eq (2) which can be used to predict the apparent specific 351 surface area for a Pt-ZSM-5-LL sample exposed to temperature, $\mathrm{T}$, and time, $\mathrm{t}$, within a range 352 close to those described. Here, $A_{s p o}$ is the specific surface area of a sample that has not 353 experienced decay.

$$
A_{s p}(t, T)=A_{s p 0}+(C \cdot t) e^{-\frac{E_{A}}{(R \cdot T)}}
$$


355 Experimental values of the surface area and the predicted values using Eq (2) are displayed in

356 Figure 15. A good fit is obtained at intermediate temperatures, which is the region where the 357 specific surface area degrades significantly. The fit fails at higher temperatures likely because 358 pore collapse drastically changes the geometry of the surface being interrogated by gas 359 molecules employed for the area measurement.

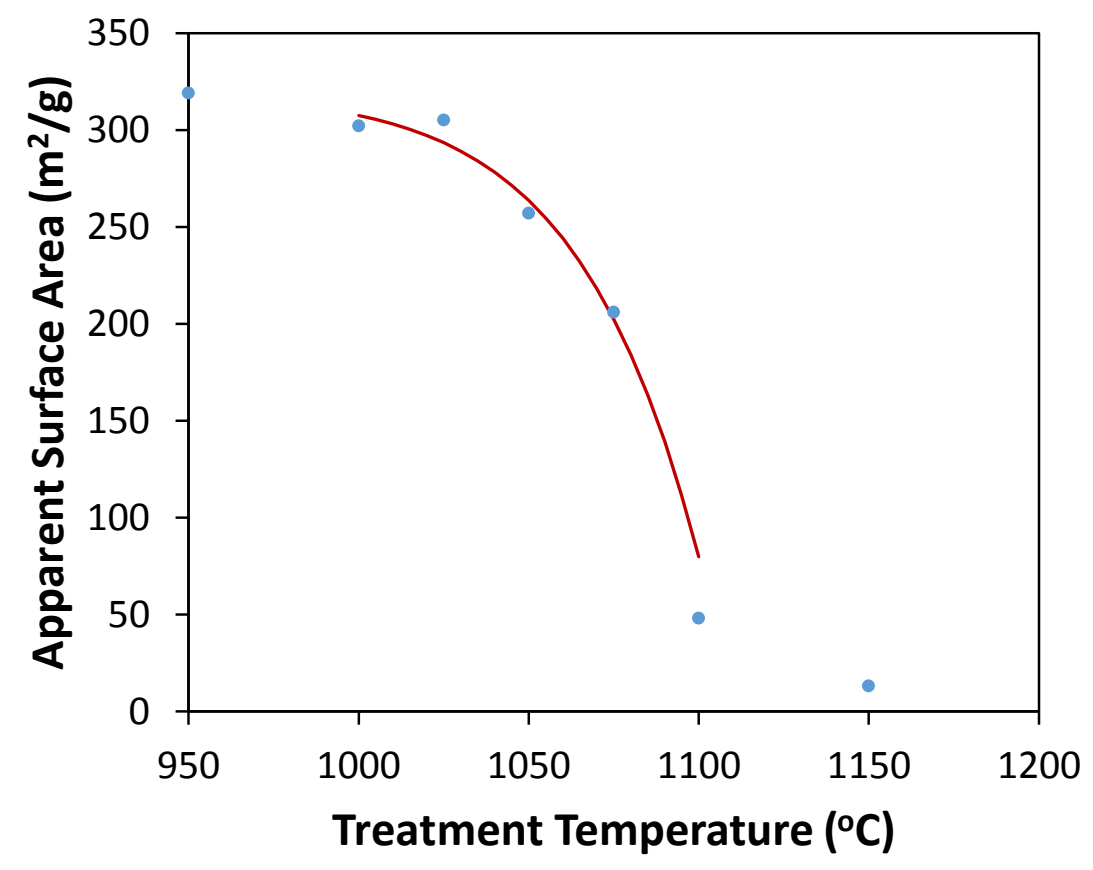

Figure 15: Relationship of the apparent specific surface area with the temperature of Pt-ZMS-5.

\section{CONCLUSION}

364 The gas adsorption, chemical and structural properties of commercial zeolite ZSM-5 and a Pt 365 loaded variant (Pt-ZSM-5) have been observed as a function of temperature. These materials 366 have an specific surface area between 300 and $400 \mathrm{~m}^{2} / \mathrm{g}$, as determined by nitrogen adsorption 367 using the BET method. Measured XRD spectra are typical for ZSM-5 zeolites. ZSM-5 is 
368 chemically and structurally stable in air up to $750{ }^{\circ} \mathrm{C}$, while Pt-ZSM-5 is stable to about $800{ }^{\circ} \mathrm{C}$.

369 Above these temperatures the porous framework of the zeolites begins to degrade.

370 Degradation of zeolites at temperatures above $800{ }^{\circ} \mathrm{C}$ was studied: samples were heated up to

$3711500{ }^{\circ} \mathrm{C}$. BET experiments were carried out at room temperature to determine the adsorptive

372 properties of the heat treated zeolites. The specific surface area decreases with increasing

373 treatment temperature. Nitrogen adsorption data indicate that heating samples to $1500{ }^{\circ} \mathrm{C}$

374 causes the porous network to collapse. XRD patterns show that at high temperature ZSM-5

375 transitions to cristobalite. Only small differences are observed between the ZSM-5 and the Pt-

376 ZSM-5

377 Adsorption studies with helium, argon and nitrogen at room temperatures were performed

378 with the zeolites Pt-ZSM-5 treated at 800,1200 , and $1500{ }^{\circ} \mathrm{C}$. The results show that the

379 quantity of adsorbed helium is higher than nitrogen and argon, and that argon adsorbs the

380 least. When the temperature increases, the pores collapse and impede access to the interior

381 structure. Importantly, the small helium atoms retain access to the densified material.

382 An Arrhenius model was developed to characterize the degradation of zeolite in nitrogen at 383 high temperatures. Collapse of the pore structure and the degradation of the specific surface 384 area start at about $1000^{\circ} \mathrm{C}$ and is complete at $1150{ }^{\circ} \mathrm{C}$. The decay of the apparent specific area 385 depends on the temperature and this dependence follows the Arrhenius equation. The 386 relationship between the surface area and the treatment temperature permits prediction of the 387 specific surface area of Pt loaded ZSM-5 sample as a function of temperature. 
This work has useful implications for nuclear fuel applications where gas capture at high temperatures may be needed. The zeolites appear to retain measureable helium incorporation even after being processed at $1500{ }^{\circ} \mathrm{C}$, in the temperature range of $\mathrm{UO}_{2}$ fuel sintering.

Nanostructured zeolites particles, appropriately distributed within fuel pellets, may therefore

provide utility for helium sequestration in operational reactors. Although additional studies are

needed to establish the full potential of this approach, the data are encouraging and merit

further consideration for this application.

\section{ACKNOWLEDGEMENTS}

This material is based upon work supported by the Department of Energy [National Nuclear Security Administration] under Award Number DE-NE0000704.

\section{REFERENCES}

[1] In: Rouquerol F, Rouquerol J, Sing K, (editors). Adsorption by Powders and Porous Solids: Principles, Methodology and Applications. London: Academic Press; 1999.

[2] Zacharie I, Lansiart S, Combette P, Trotabas M, Coster M, Groos M. Microstructural analysis and modelling of intergranular swelling of an irradiated UO2 fuel treated at high temperature. Journal of Nuclear Materials. 1998;255:92-104.

[3] Roudil D, Deschanels X, Trocellier P, Jegou C, Peuget S, Bart JM. Helium thermal diffusion in a uranium dioxide matrix (vol 325, pg 148, 2004). Journal of Nuclear Materials. 2004;327:226-.

408 [5] Ferry C, Piron J-P, Ambard A. Effect of helium on the microstructure of spent fuel in a repository: An operational approach. Journal of Nuclear Materials. 2010;407:100-9.

[6] World Nuclear Association Nuclear Fuel Fabrication.

[7] Balakrishna P, Asnani CK, Kartha R, Ramachandran K, Babu KS, Ravichandran V, et al. Uranium dioxide powder preparation, pressing, and sintering for optimum yield. Nuclear technology. 1999;127:375-81.

[8] Logar NZ, Kaucic V. Nanoporous materials: From catalysis and hydrogen storage to wastewater treatment. Acta chimica slovenica. 2006;53:117.

[9] Satterfield CN. Heterogeneous catalysis in industrial practive. 2 nd ed1994.

[10] Morris RE, Wheatley PS. Gas storage in nanoporous materials. Angewandte Chemie International Edition. 2008;47:4966-81.

[11] Adiga SP, Jin C, Curtiss LA, Monteiro-Riviere NA, Narayan RJ. Nanoporous membranes for medical and biological applications. Wiley Interdisciplinary Reviews: Nanomedicine and Nanobiotechnology. 2009;1:568-81. 
[12] Byrne JW, Chen JM, Speronello BK. Selective catalytic reduction of NOx using zeolitic catalysts for high temperature applications. Catalysis Today. 1992;13:33-42.

[13] Wang L, Tao L, Xie M, Xu G, Huang J, Xu Y. Dehydrogenation and aromatization of methane under non-oxidizing conditions. Catal Lett. 1993;21:35-41.

[14] Muller JCM, Hakvoort G, Jansen JC. DSC and TG Study of Water Adosorption and Desorption on Zeolite $\mathrm{NaA}$ Powder and attached as layer on metal. Journal of Thermal Analysis and Calorimetry. 1998;53:449-66.

[15] Csicsery SM. Shape-selective catalysis in zeolites. Zeolites. 1984;4:202-13.

[16] Du X, Wu E. Porosity of microporous zeolites A, X and ZSM-5 studied by small angle X-ray scattering and nitrogen adsorption. Journal of Physics and Chemistry of Solids. 2007;68:1692-9.

[17] Dyer A, Gawad ASA, Mikhail M, Enamy H, Afshang M. The natural zeolite, laumontite, as a potential material for the treatment of aqueous nuclear wastes. Journal of Radioanalytical and Nuclear Chemistry Letters. 1991;154:265-76.

[18] Dyer A, Keir D. NUCLEAR WASTE TREATMENT BY ZEOLITES. Zeolites. 1984;4:215-7.

[19] Shigeishi RA, Langford CH, Hollebone BR. SOLAR-ENERGY STORAGE USING CHEMICAL-POTENTIAL CHANGES ASSOCIATED WITH DRYING OF ZEOLITES. Solar Energy. 1979;23:489-95.

[20] Robert J. argauer K, Md., and George R. Landolt, Audobon, N.J., assignors to Mobil Oil Corporation. Crystalline zeolite ZSM-5 and method of preparing the same. In: corporation MO, (editor). United States Patent Office. United Stat1967.

[21] Hong S, Uh Y, Woo S, Lee J. Thermal stability of [B]ZSM-5 molecular sieve. Korean J Chem Eng. 1991;8:1-5.

[22] Tallon JL, Buckley RG. THERMAL-DECOMPOSITION OF THE ZEOLITE CATALYST ZSM-5. Journal of Physical Chemistry. 1987;91:1469-75.

[23] Kokotailo GT, Lawton SL, Olson DH, Meier WM. Structure of synthetic zeolite ZSM-5. Nature. 1978;272:437-8.

[24] Sang SY, Chang FX, Liu ZM, He CQ, He YL, Xu L. Difference of ZSM-5 zeolites synthesized with various templates. Catalysis Today. 2004;93-5:729-34.

[25] Sebastian J, Peter SA, Jasra RV. Adsorption of Nitrogen, Oxygen, and Argon in Cobalt(II)-Exchanged Zeolite X. Langmuir. 2005;21:11220-5.

[26] Trigueiro FE, Monteiro DFJ, Zotin FMZ, Sousa-Aguiar EF. Thermal stability of Y zeolites containing different rare earth cations. Journal of Alloys and Compounds. 2002;344:337-41.

[27] Sing KSW, Everett DH, Haul RAW, Moscou L, Pierotti RA, Rouquerol J, et al. REPORTING PHYSISORPTION DATA FOR GAS SOLID SYSTEMS WITH SPECIAL REFERENCE TO THE DETERMINATION OF SURFACE-AREA AND POROSITY (RECOMMENDATIONS 1984). Pure and Applied Chemistry. 1985;57:60319.

[28] Bae Y-S, Yazaydın AÖ, Snurr RQ. Evaluation of the BET Method for Determining Surface Areas of MOFs and Zeolites that Contain Ultra-Micropores. Langmuir. 2010;26:5475-83.

[29] Brunauer S, Emmett PH, Teller E. Adsorption of Gases in Multimolecular Layers. Journal of the American Chemical Society. 1938;60:309-19.

[30] Jardim PM, Marinkovic BA, Saavedra A, Lau LY, Baehtz C, Rizzo F. A comparison between thermal expansion properties of hydrated and dehydrated orthorhombic HZSM-5 zeolite. Microporous and Mesoporous Materials. 2004;76:23-8.

[31] Song W, Justice RE, Jones CA, Grassian VH, Larsen SC. Synthesis, Characterization, and Adsorption Properties of Nanocrystalline ZSM-5. Langmuir. 2004;20:8301-6.

[32] Hardenberg TAJ, Mertens L, Mesman P, Muller HC, Nicolaides CP. A CATALYTIC METHOD FOR THE QUANTITATIVE-EVALUATION OF CRYSTALLINITIES OF ZSM-5 ZEOLITE PREPARATIONS. Zeolites. 1992;12:685-9. 
[33] Santhosh Kumar M, Holmen A, Chen D. The influence of pore geometry of Pt containing ZSM-5, Beta and SBA-15 catalysts on dehydrogenation of propane. Microporous and Mesoporous Materials. 2009;126:152-8.

[34] Villegas JI, Kumar N, Heikkilä T, Lehto VP, Salmi T, Murzin DY. Isomerization of n-butane to isobutane over Pt-modified Beta and ZSM-5 zeolite catalysts: Catalyst deactivation and regeneration. Chemical Engineering Journal. 2006;120:83-9.

[35] Sing K. The use of nitrogen adsorption for the characterisation of porous materials. Colloids and Surfaces A: Physicochemical and Engineering Aspects. 2001;187-188:3-9.

[36] Conner WMC. Analyses of (AD)-Sorption for the Estimation of Pore-Network Dimensions and Structure. Journal of Porous Materials. 1995;2:191-9.

[37] Sing KSW. Adsorption methods for the characterization of porous materials. Advances in Colloid and Interface Science. 1998;76-77:3-11.

[38] Russel WW. The Adsorption of Gases and Vapors. Volume I: Physical Adsorption (Brunauer, Stephen). Journal of Chemical Education. 1944;21:52.

[39] Sing KSW. Characterization of porous materials: past, present and future. Colloids and Surfaces A: Physicochemical and Engineering Aspects. 2004;241:3-7.

[40] Thommes M. Physical Adsorption Characterization of Nanoporous Materials. Chemie Ingenieur Technik. 2010;82:1059-73.

[41] Wu S-H, Hsieh C-C, Chiang C-C, Horng J-J, Pan W-P, Shu C-M. Thermal analyses of home-made zeolite by DSC and TG. Journal of Thermal Analysis and Calorimetry. 2012;109:945-50.

[42] Aboulgheit AK, Alhajjaji MA, Summan AM, Abdelhamid SM. DIFFERENTIAL SCANNING CALORIMETRY LEADS TO HIGH-PRECISION FOR WATER IN ZEOLITES DETERMINED BY THERMOGRAVIMETRY. Thermochimica Acta. 1988;126:397-402.

[43] Matteucci S, Yampolskii Y, Freeman BD, Pinnau I. Transport of gases and vapors in glassy and rubbery polymers. Materials science of membranes for gas and vapor separation. 2006;1:47.

[44] John W. Anthony RAB, Kenneth W. Bladh, Monte c. Nichols. Handbook of Mineralogy. Chantilly, VA 20151-1110, USA: Mineralogical Society of America; 2001.

[45] Arrhenius S. On the reaction rate of the inversion of non-refined sugar upon souring. Z Phys Chem. 1889;4:226-48. 